\title{
Front Matter: Volume 10225
}

, "Front Matter: Volume 10225," Proc. SPIE 10225, Eighth International Conference on Graphic and Image Processing (ICGIP 2016), 1022501 (13 February 2017); doi: 10.1117/12.2271086

SPIE Event: Eighth International Conference on Graphic and Image Processing, SPIE. 2016, Tokyo, Japan 


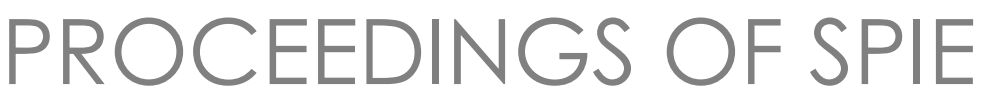

\title{
Eighth International Conference on Graphic and Image Processing (ICGIP 2016)
}

\author{
Tuan D. Pham \\ Vit Vozenilek \\ Zhu Zeng \\ Editors
}

29-31 October 2016

Tokyo, Japan

Organized by

International Association of Computer Science and Information Technology, Singapore

Sponsored by

University of Aizu (Japan)

Wuhan University (China)

Linkoping University (Sweden)

Palacky University (Czech Republic)

Published by

SPIE

Volume 10225 
The papers in this volume were part of the technical conference cited on the cover and title page. Papers were selected and subject to review by the editors and conference program committee. Some conference presentations may not be available for publication. Additional papers and presentation recordings may be available online in the SPIE Digital Library at SPIEDigitallibrary.org.

The papers reflect the work and thoughts of the authors and are published herein as submitted. The publisher is not responsible for the validity of the information or for any outcomes resulting from reliance thereon.

Please use the following format to cite material from these proceedings:

Author(s), "Title of Paper," in Eighth International Conference on Graphic and Image Processing (ICGIP 2016), edited by Tuan D. Pham, Vit Vozenilek, Zhu Zeng, Proceedings of SPIE Vol. 10225 (SPIE, Bellingham, WA, 2017) Seven-digit article CID Number.

ISSN: 0277-786X

ISSN: 1996-756X (electronic)

ISBN: 9781510609518

ISBN: 9781510609525 (electronic)

Published by

SPIE

P.O. Box 10, Bellingham, Washington 98227-0010 USA

Telephone +1 3606763290 (Pacific Time) · Fax +1 3606471445

SPIE.org

Copyright @ 2017, Society of Photo-Optical Instrumentation Engineers.

Copying of material in this book for internal or personal use, or for the internal or personal use of specific clients, beyond the fair use provisions granted by the U.S. Copyright Law is authorized by SPIE subject to payment of copying fees. The Transactional Reporting Service base fee for this volume is $\$ 18.00$ per article (or portion thereof), which should be paid directly to the Copyright Clearance Center (CCC), 222 Rosewood Drive, Danvers, MA 01923. Payment may also be made electronically through CCC Online at copyright.com. Other copying for republication, resale, advertising or promotion, or any form of systematic or multiple reproduction of any material in this book is prohibited except with permission in writing from the publisher. The CCC fee code is 0277-786X/17/\$18.00.

Printed in the United States of America.

Publication of record for individual papers is online in the SPIE Digital Library.

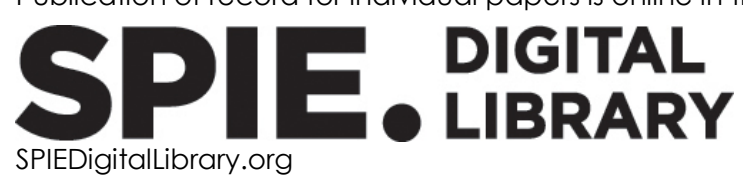

Paper Numbering: Proceedings of SPIE follow an e-First publication model. A unique citation identifier (CID) number is assigned to each article at the time of publication. Utilization of CIDs allows articles to be fully citable as soon as they are published online, and connects the same identifier to all online and print versions of the publication. SPIE uses a seven-digit CID article numbering system structured as follows:

- The first five digits correspond to the SPIE volume number.

- The last two digits indicate publication order within the volume using a Base 36 numbering system employing both numerals and letters. These two-number sets start with 00, 01, 02, 03, 04, 05, 06, 07, 08, 09, OA, OB ... 0Z, followed by 10-1Z, 20-2Z, etc. The CID Number appears on each page of the manuscript. 


\title{
Contents
}

\author{
ix Authors \\ xiii Conference Committee \\ $\mathrm{xV}$ Introduction
}

SECTION 1 FEATURE EXTRACTION AND PATTERN MATCHING

1022502 Feature extraction using gray-level co-occurrence matrix of wavelet coefficients and texture matching for batik motif recognition [10225-79]

1022503 Fast template matching based on grey prediction for real-time object tracking [10225-22]

1022504 Object tracking via kernel-based forward-backward keypoint matching [10225-43]

$1022505 \quad$ Navigable points estimation for mobile robots using binary image skeletonization [10225-98]

1022506 Using the erroneous data clustering to improve the feature extraction weights of original image algorithms [10225-6]

1022507 An improved RANSAC algorithm for line matching on multispectral images [10225-46]

1022508 Automatic detection and extraction of ultra-fine bright structure observed with new vacuum solar telescope [10225-96]

\section{SECTION 2 TARGET DETECTION AND RECOGNITION}

1022509 Unconstrained face detection and recognition based on RGB-D camera for the visually impaired [10225-18]

10225 OA Gait recognition based on integral outline [10225-21]

10225 OB Deep learning and non-negative matrix factorization in recognition of mammograms [10225-32]

10225 OC TDSIFT: a new descriptor for 2D and 3D ear recognition [10225-55]

10225 OD Pre-impact fall detection system using dynamic threshold and 3D bounding box [10225-66]

10225 OE Overhead spine arch analysis of dairy cows from three-dimensional video [10225-5]

10225 OF Real time lobster posture estimation for behavior research [10225-40] 
$102250 G$ Face recognition based on the band fusion of generalized phase spectrum of 2D-FrFT [10225-41]

$10225 \mathrm{OH}$ Arabic sign language recognition based on HOG descriptor [10225-45]

10225 Ol Kinect-based sign language recognition of static and dynamic hand movements [10225-56]

10225 0J Emotion detection model of Filipino music [10225-58]

10225 OK Tele-operated search robot for human detection using histogram of oriented objects [10225-78]

$10225 \mathrm{OL}$ The identification of molecular surfaces' feature regions based on spherical mapping [10225-85]

$102250 \mathrm{M}$ Support vector machine and mel frequency Cepstral coefficient based algorithm for hand gestures and bidirectional speech to text device [10225-91]

10225 ON Circle Hough transform implementation for dots recognition in braille cells [10225-93]

1022500 Error-detective one-dimensional mapping [10225-103]

10225 OP A scale-invariant keypoint detector in log-polar space [10225-104]

$102250 Q$ An automated detection for axonal boutons in vivo two-photon imaging of mouse [10225-107]

\section{SECTION 3 IMAGE TRANSFORMATION AND ANALYSIS}

10225 OR Two-stage underwater image restoration based on a physical model [10225-50]

10225 OS An evaluation on CT image acquisition method for medical VR applications [10225-60]

10225 OT Mosaicing of fisheye images through conformal projection and sphere matching [10225-42]

$10225 \mathrm{OU}$ A liver cirrhosis classification on B-mode ultrasound images by the use of higher order local autocorrelation features [10225-73]

10225 OW Extended gray level co-occurrence matrix computation for 3D image volume [10225-87]

$102250 X$ Classification of photographed document images based on deep-learning features [10225-90]

10225 OY An improved the volume trace transform by a sub-micro pattern for solving the Gaussian noise image problem [10225-117]

$102250 Z$ An effective image classification method with the fusion of invariant feature and a new color descriptor [10225-71] 
1022510 A multi-label image annotation scheme based on improved SVM multiple kernel learning [10225-8]

1022511 Multi-frame blind image deconvolution through split frequency - phase recovery [10225-30]

1022512 High resolution OCT image generation using super resolution via sparse representation [10225-33]

\section{SECTION 4 IMAGE SEGMENTATION}

1022513 Various uses of statistical tools for texture analysis [10225-39]

1022514 Bounded Rayleigh mixture model for ultrasound image segmentation [10225-84]

102215 Multi-scales region segmentation for ROI separation in digital mammograms [10225-100]

1022516 Omega-3 chicken egg detection system using a mobile-based image processing segmentation method [10225-3]

1022517 Surgical wound segmentation based on adaptive threshold edge detection and genetic algorithm [10225-9]

1022518 SOM-based nonlinear least squares twin SVM via active contours for noisy image segmentation [10225-24]

1022519 Novel approach for automatic segmentation of LV endocardium via SPCNN [10225-31]

10225 1A Handwritten text line segmentation by spectral clustering [10225-89]

SECTION 5 IMAGE RECONSTRUCTION AND IMAGE SECURITY

10225 1B Image steganography using layered pixel-value differencing [10225-35]

10225 1C Fingerprint spoof detection using wavelet based local binary pattern [10225-69]

10225 ID Image watermarking against lens flare effects [10225-77]

$10225 \mathrm{IE}$ Indoor space 3D visual reconstruction using mobile cart with laser scanner and cameras [10225-51]

10225 IF Robust optical flow using adaptive Lorentzian filter for image reconstruction under noisy condition [10225-54]

$102251 G$ The ultra-rate spatial enhancement using Huber regularization MSRR and Huber highspectrum expectation [10225-65] 
$102251 \mathrm{H} \quad$ Estimating 3D gaze in physical environment: a geometric approach on consumer-level remote eye tracker [10225-12]

1022511 An add-on video compression codec based on content-adaptive sparse super-resolution reconstructions [10225-15]

$102251 \mathrm{~J}$ Sample-adaptive-prediction for HEVC SCC intra coding with ridge estimation from spatially neighboring samples [10225-16]

$102251 \mathrm{~K}$ A neighbor pixel communication filtering structure for Dynamic Vision Sensors [10225-26]

$102251 \mathrm{~L}$ Detecting dominant motion patterns in crowds of pedestrians [10225-67]

$102251 \mathrm{M} \quad$ Visual identification and similarity measures used for on-line motion planning of autonomous robots in unknown environments [10225-94]

$102251 \mathrm{~N}$ Color image zero-watermarking based on SVD and visual cryptography in DWT domain [10225-99]

1022510 Multiple candidates and multiple constraints based accurate depth estimation for multiview stereo [10225-102]

10225 IP An improved TLD with Harris corner and color moment [10225-110]

$102251 Q \quad$ The software for automatic creation of the formal grammars used by speech recognition, computer vision, editable text conversion systems, and some new functions [10225-112]

10225 IR Measuring tail beat frequency and coast phase in school of fish for collective motion analysis [10225-44]

10225 is Head pose free 3D gaze estimation using RGB-D camera [10225-4]

10225 IT IECDS: an improved electrical charge distribution on the shape [10225-10]

SECTION 7 IMAGE PROCESSING AND APPLICATION

$102251 \mathrm{U}$ Landscape analysis through remote sensing and GIS techniques: a case study of Astrakhan, Russia [10225-27]

$102251 \mathrm{~V}$ Deep learning in assessment of drill condition on the basis of images of drilled holes [10225-29]

$102251 \mathrm{~W} \quad$ Cloud-based application for rice moisture content measurement using image processing technique and perceptron neural network [10225-80]

$102251 \mathrm{X} \quad$ Low cost 3D scanning process using digital image processing [10225-92] 
10225 IY Behavioral similarity measurement based on image processing for robots that use imitative learning [10225-97]

1022512 Selection of achromatic and non-neutral colors to fill lacunae in frescoes guided by a variational model of perceived contrast [10225-116]

1022520 Scene classification for weak devices using spatial oriented gradient indexing [10225-19]

1022521 Visualization and processing of images in nano-resolution [10225-70]

1022522 Temperature and oxygen visual estimator for carbonization process control [10225-95]

1022523 The simulation of the half-dry stroke based on the force feedback technology [10225-34]

1022524 Surface height map estimation from a single image using convolutional neural networks [10225-48]

1022525 Discriminant analysis of multiple cortical changes in mild cognitive impairment [10225-25]

SECTION 8 MEDICAL IMAGE PROCESSING

1022526 Automatic wound infection interpretation for postoperative wound image [10225-13]

1022527 Automatic right ventricle segmentation in cardiac MRI via anisotropic diffusion and SPCNN [10225-17]

1022528 CUDA-based acceleration of collateral filtering in brain MR images [10225-74]

1022529 A new boundary correction method for lung parenchyma [10225-2]

10225 2A Evaluation of feature selection algorithms for classification in temporal lobe epilepsy based on MR images [10225-36]

10225 2B Detection of tuberculosis using hybrid features from chest radiographs [10225-62]

10225 2C Regions of micro-calcifications clusters detection based on new features from imbalance data in mammograms [10225-72]

10225 2D Recursive Gauss-Seidel median filter for CT lung image denoising [10225-86]

$102252 \mathrm{E}$ Determining the number of clusters for nuclei segmentation in breast cancer image [10225-88]

$102252 \mathrm{~F} \quad$ Link prediction boosted psychiatry disorder classification for functional connectivity network [10225-115] 
10225 2G 3D kinematic measurement of human movement using low cost fish-eye cameras [10225-49]

$102252 \mathrm{H} \quad$ Foreground extraction for moving RGBD cameras [10225-14]

$1022521 \quad$ Analyzing machine noise for real time maintenance [10225-11]

10225 2J An interpretation model of GPR point data in tunnel geological prediction [10225-23]

$102252 \mathrm{~K}$ Optimization of deep learning algorithms for object classification [10225-38] 


\section{Authors}

Numbers in the index correspond to the last two digits of the six-digit citation identifier (CID) article numbering system used in Proceedings of SPIE. The first four digits reflect the volume number. Base 36 numbering is employed for the last two digits and indicates the order of articles within the volume. Numbers start with 00, 01, 02, 03, 04, 05, 06, 07, 08, 09, OA, OB...0Z, followed by 10-1Z, 20-2Z, etc.

Abdul Jabbar, K., OE

Abela, John, 11

Abina, Jyacinth Camille F., OK

Aguilar, David, $1 \mathrm{X}$

Ahmed, Naveed, $2 \mathrm{H}$

Akhtar, Mahmood, 2B

Akram, Muhammad Usman, 12, 2B

Alfredsen, Jo Arve, OF

Amornraksa, Thumrongrat, 1D

Aoki, Ryota, 1E

Asif, Muhammad, 12

Asikuzzaman, Md., $2 \mathrm{G}$

Avellanosa, James Jason G., OK

Avendaño, Glenn O., OK

Azman, Azreen, $\mathrm{OZ}$

Balbin, Jessie R., OM

Bao, Di, IP

Barhoumi, Walid, OB

Ben Hamadou, Abdelmajid, $\mathrm{OH}$

Ben Jemaa, Yousra, $\mathrm{OH}$

Ben Jmaa, Ahmed, $\mathrm{OH}$

Bi, H., 14

Blumenstein, Michael, $1 \mathrm{~L}$

Boonbrahm, Poonpong, OD

Boori, Mukesh Singh, $1 \mathrm{U}$

Bucog, Krissel C., IW

Cachia, Ernest, 11

Chang, Chun-Che, 17, 26

Chang, Herng-Hua, 28

Chang, Tse, 06

Chen, Beijing, $1 \mathrm{~N}$

Chen, Enqing, $0 G$

Chen, Long, OC

Chen, Xi, OQ

Chen, Xingnan, OR

Cheng, Fei, IP

Cheng, Lina, 2A

Chotikawanid, Piyanart, ID

Choudhary, Komal, $1 \mathrm{U}$

Chu, Teng-Hao, 06

Chung, Wen-Yaw, OK, IW

Coatrieux, Gouenou, IN

Collobert, Michel, is

Cruz, Febus Reidj G., OK, IW

Dalawis, Rando C., Ol

Delos Angeles, Bethsedea Joy S., OM

Deng, Linhua, 08

Dewi, Dyah Ekashanti Octorina, OW, 2D

Dillenseger, J. L., 14
Dizon, Neil John A., OM

Dong, Junyu, OR, 24

Dong, Min, 2C

Du, Zhiying, 04

Durand, Philippe, 13

Fan, Chunxiao, 07

Fan, $\mathrm{HaO}, \mathrm{OR}$

Fang, LV, OA

Fatichah, Chastine, 2E

Fatima, Ayesha, 2B

Faudzi, Ahmad Athif Mohd., 2D

Fausto, Janette C., OM

Fujita, Yusuke, oU

Fukumoto, Yoshifumi, 2 I

Garcia, Ramon G., OM

Garratt, Matthew A., 2G

Gashongore, Prince Dukundane, 1E

Gauci, Adam, 11

Ghorbanzadeh, Dariush, 13

Grementieri, Luca, 12

Gulua, Nana, 1Q

Guo, Chao, 23

Guo, Shengwen, 25, 2A

Guo, Yanan, 2C

Guo, Yuan-shu, 2J

Hamamoto, Kazuhiko, $1 \mathrm{H}$

Hamamoto, Yoshihiko, OU

Han, Hua, OQ

Han, Xuecheng, 1A

Hansen, M. F., OE

Hassan, Taimur, 12

He, Yu-yao, 2J

Herumurti, Darlis, 02

Hioki, Hirohisa, IR

Hirsch, Michael, 11

Ho, Te-Wei, 17, 26

Hong, Chen, OX

Hortinela, Carlos C. IV, IW

Horváth, András, 2K

Hou, Runmin, 03

Hou, Yuanlong, 03

Hou, Zeng-xuan, 23

Hsu, Jui-Tse, 17, 26

Hu, Weijian, 09

Huang, Jiashuang, $2 F$

Isidro, Daryl Arvin, 0J

Islam, Atiqul, 2G

Isshiki, Tsuyoshi, 1C

Jacinto Gómez, Edwar, 05, 0N, 1M, IY 
Jang, Seong-wook, OS Jaupi, Luan, 13 Jegorowa, Albina, IV Jiang, Huiqin, 29 Jiang, Jianmin, 11 Jiang, Xingjun, 25 Jin, Cong, 10 Jin, Shu-Wei, 10 Jundang, Nattapong, OY Junejo, Imran N., $2 \mathrm{H}$ Jurga, Stefan, 1Q Kacete, Amine, $1 \mathrm{~S}$ Kang, Je-Won, $1 \mathrm{~J}$ Kardava, Irakli, 1Q Kawasue, Kikuhito, $1 \mathrm{E}$ Kesrarat, Darun, IF Khan, Sultan Daud, $1 \mathrm{~L}$ Kim, Jaeyoung, 1B Kim, Yoonsang, OS Ko, Junho, OS Kruk, Michal, OB, IV Kumazaki, Hiroki, 2 I Kumpituck, Supawan, 1C Kunieda, Hiroaki, 1C Kupriyanov, Alexander, IU Kurek, Jaroslaw, OB, $1 \mathrm{~V}$ Lai, Chunren, 25, 2A Lai, Feipei, 17, 26 Lei, Ruoming, 19, 27 Li, Bao-qi, 2J Li, Cheng-Yuan, 28 Li, Dongju, 1C Li, Jing, OT

Li, Ling, IP

Li, Weifu, OQ

Li, Weiwei, $2 \mathrm{~F}$

Li, Yong, 07

Li, Yue, 15

Li, Zhiyang, $1 T$

Liang, Junfang, 29

Liu, Jia, OT

Liv, Kai, IP

Liu, Rongzhong, 03

Liu, Shiqi, 1K

Liu, Xilin, $1 \mathrm{~N}$

Liu, Yu, OT

Liu, Yumin, 29

Liu, Yutong, OX

Liv, Zhaobin, $1 T$

Lu, Hehui, 1K

Lv, Mingming, 03

M., Kurniawan Teguh, 16

Ma, Ling, 29

Ma, Minmin, 1T

Ma, Yide, 19, 27, 2C

Ma, Yurun, 19, 27

Mahdi, Walid, $\mathrm{OH}$

Mahesa, Rizki R., $1 \mathrm{H}$

Manlises, Cyrel O., OK

Mansourian, Leila, $\mathrm{OZ}$
Mao, Jianzhou, 24

Mardo, Mark Kevin N., OM

Martínez Santa, Fernando, 05, 1M, 1X, 1Y, 22

Martínez Sarmiento, Fredy Hernán, ON, 1M, 22

Masaquel, Albert M., OK

Mei, Xue, 2F

Mengko, Tati Latifah, 2D

Ming, Guan, OA

Mitani, Yoshihiro, OU

Montiel Ariza, Holman, 05, 0N, 22

Mu, Zhichun, OC

Mustaffa, Mas Rina, $\mathrm{OZ}$

Nan, Bingfei, OC

Navastara, Dini Adni, 2E

Noblejas, Kathleen Alexis, 0J

Nugroho, Hanung A., $1 \mathrm{H}$

Nuraini, Lubna, 2E

Nurhayati, Oky Dwi, 16

Nurliyana Abdullah, Lili, $\mathrm{OZ}$

Olayao, Kenneth Deniel R., Ol

Ongkittikul, Surachai, OY

Osowski, Stanislaw, OB, IV

Otanasap, Nuth, OD

P., Cintya Amalia, 16

Padilla, Dionis A., OM, IW

Park, Hanhoon, 1B

Patanavijit, Vorapoj, 1F, IG

Pham, Tuan D., OX, 24

Phung, Minh Tung, 20

Pickering, Mark R., 2G

Pour, Tomas, 21

Provenzi, Edoardo, 1 Z

Qi, Lin, OG

Qi, Lin, OR, 24

Qu, Wenyu, 1T

Ramos, Evan Geoffrey I., Ol

Romero, Carlos, $1 \mathrm{X}$

Royan, Jérôme, $1 \mathrm{~S}$

Ryu, Soo-Kyung, $1 \mathrm{~J}$

Sakagami, Masa-aki, IR

Sakaida, Isao, OU

Salih, Nurulazirah M., OW

Samonte, Mary Jane C., Ol, OJ

Saqib, Muhammad, IL

Sarto, Mildred C., IW

Sasaki, Kenya, OU

Séguier, Renaud, 1S

Shafique, Irrum, 2B

Shaukat, Arslan, 12

Shih, Hsueh-Fu, 17, 26

Shu, Huazhong, 14, 1N

Sia, Nirlu Sebastian A., IW

Siapno, Michael Lance O., OK

Smith, L. N., OE

Smith, M. L., OE

Srisuk, Sanun, OY

Sterpin B., Dante G., $1 Y$

Suciati, Nanik, 02, 2E

Sun, Huijing, OG

Sun, Mingui, 04 
Suzumori, Koichi, 2D

Swiderski, Bartosz, OB, IV

Tadyszak, Krzysztof, 1Q

Tang, H., 14

Tao, Tao, OP

Taufik Abdullah, Muhamad, $\mathrm{OZ}$

Terayama, Kei, 1R

Tie, Yun, 0G

Toshiya, Nakaguchi, 29

Tu, Trung Hieu, 20

Vergara, Ernesto M. Jr., OM

Vozenilek, Vit, 21

Wang, Deyuan, 19

Wang, Hao, $2 \mathrm{~F}$

Wang, Kaiwei, 09

Wang, Keju, 2C

Wang, Kemin, 19, 27

Wang, Nan, OR

Wang, Teng-na, 2J

Wang, Tingting, 18

Wang, Wei, 15

Wang, Wensheng, $2 \mathrm{~A}$

Wang, Xu, OG

Waqar, Razi, 12

Wei, Lijun, 07

Wibirama, Sunu, $1 \mathrm{H}$

Wijaya, Arya Yudhi, 02

Wu, Congling, 25

Wu, Jin-Ming, 17, 26

Wu, Junfeng, $1 \mathrm{~T}$

Wu, Kai, 2A

Wu, Tin-Yu, 06

Wu, Yupeng, 25

Xie, Qiwei, $0 Q$

Xie, Xiaomin, 18

$X U$, Liangpeng, 07

Xu, Wei, OT

$X U$, Yuan, $1 \mathrm{~K}$

Xue, Bindang, 10

Yamato, Yoji, 21

Yan, Sheng, OF

Yang, Guang-ging, 23

Yang, Kailun, 09

Yang, Ruyin, OC

Yang, Shu, 11

Yang, Zhen, 27, 2C

Yao, Hui, OX, $1 \mathrm{~A}$

Yoo, Yon-sik, OS

Yoshida, Kumiko, $1 \mathrm{E}$

Yu, Hang, 07

Yu, Hui, OR

Yuan, Ding, 04

ZarbAdami, Kristian, 11

Zhang, Chao, 10

Zhang, Dandan, $0 Q$

Zhang, Dapeng, 15

Zhang, Di, 15

Zhang, Hong, 04

Zhang, Jingqiao, OL

Zhang, Maojun, OT
Zhang, Meiling, OL

Zhang, Yi, OC

Zhang, Yun, OO, OP

Zhang, Zilong, $1 \mathrm{~K}$

Zhao, Di, 25

Zhao, Qi, 04

Zhao, Xiangdong, 09

Zheng, Shuan-zhu, 23

Zhong, Guoqiang, 0X, 1A, 24

Zhou, Fugen, 10

Zhou, Shihao, 00

Zhou, Xiaowei, 24

Zhou, Yu, 2F

Zhu, Ya, 2J 
Proc. of SPIE Vol. 10225 1022501-12 Downloaded From: https://www.spiedigitallibrary.org/conference-proceedings-of-spie on 26 Apr 2023
Terms of Use: https://www.spiedigitallibrary.org/terms-of-use 


\section{Conference Committee}

Advisory Committee

David Zhang, Hong Kong Polytechnic University (Hong Kong)

Godfried T. Toussaint, New York University Abu Dhabi (UAE)

Josef Kittler, University of Surrey (United Kingdom)

Conference Chairs

Tuan D. Pham, Linkoping University (Sweden)

Vit Vozenilek, Palacky University (Czech Republic)

Program Committee

Feng Tian, Bournemouth University (United Kingdom)

Hui Yu, University of Portsmouth (United Kingdom)

Hayato Ohwada, Tokyo University of Science (Japan)

Session Chairs

1 Pattern Recognition

Vit Vozenilek, Palacky University (Czech Republic)

2 Signal processing and computer science

András Horváth, Peter Pazmany Catholic University (Hungary)

3 Computer Vision and Video Processing

Je-Won Kang, Ewha Womans University (Korea)

$4 \quad$ Image Segmentation

Tuan D. Pham, Linkoping University (Sweden)

$5 \quad$ Image Analysis

Thumrongrat Amornraksa, King Mongkut's University of Technology Thonburi (Thailand)

6 Target Detection and Image Information on Security

Jessie R. Balbin, Mapua Institute of Technology (Philippines)

$7 \quad$ Image processing technology and application

Muhamad Taufik Abdullah, University Putra Malaysia (Malaysia) 
Proc. of SPIE Vol. 10225 1022501-14 Downloaded From: https://www.spiedigitallibrary.org/conference-proceedings-of-spie on 26 Apr 2023
Terms of Use: https://www.spiedigitallibrary.org/terms-of-use 


\section{Introduction}

\section{Dear Distinguished Delegates and Guests,}

It was a great pleasure for us to organize 2016 8th International Conference on Graphic and Image Processing (ICGIP 2016) from October 29-31, 2016 in Tokyo, Japan.

This conference is hosted at Hotel Sunroute Plaza Shinjuku, co-sponsored by International Association of Computer Science and Information Technology, University of Aizu, Wuhan University, Linkoping University and Palacky University.

ICGIP conference has become a popular annual event particularly attracting the young researchers. It has established itself as a world-class conference in which participants from academia and industry interact through formal presentations and informal discussions, accompanied with keynotes.

The purpose of ICGIP 2016 is to share an opportunity for researchers to introduce recent issues related to Graphic and Image Processing. It covers a broad range of topics in the field, such as Image acquisition, Pattern recognition and analysis, Signal Noise Control, Watermarking, and Nonlinear Signals and Systems, etc. We thank the members of the ICGIP 2016 committee for managing the reviews of submissions. We believe these are the main driving factors attributed to our success.

This year 171 papers were submitted, and all the submitted papers in the proceeding have been peer reviewed by the reviewers drawn from the scientific committee, external reviewers and editorial board depending on the subject matter of the paper. Reviewing and initial selection were undertaken electronically. After the rigorous peer-review process, the submitted papers were selected on the basis of originality, significance, and clarity for the purpose of the conference. We want to thank all the authors for submitting their innovative and sound work to ICGIP 2016.

Apart from Technical paper presentation, there were also keynote lectures. We are grateful to the keynote speakers for accepting our invitation. They are Prof. Tuan D. Pham from Linkoping University, Sweden, Prof. Shigeo Takahashi from University of Aizu, Japan, Prof. Patrick Wang from Northeastern University, USA, Prof. Vit Vozenilek, Palacky University from Czech Republic and Prof. Hiroshi FUJITA from Gifu University, Japan. 
We extend our gratitude to the partners and sponsors who made the events feasible. We truly believe the participants will find the discussion fruitful, and will enjoy the opportunity for setting up future collaborations. It is our sincere hope that ICGIP will one day become the leading conference in this specific academic area.

Vit Vozenilek Tuan D. Pham 